\title{
An Algorithm for Computing Significance Levels Using the Kolmogorov-Smirnov Statistic and Valid for both Large and Small Samples
}

\section{OAK} RIDGE NATIONAL LABORATORY

\section{UNION \\ CARBIDE}

S. E. Kurtz

D. E. Fields

\section{DO NOT MICROFILM THIS PAGE}

OPERATED BY

UNION CARBIDE CORPORATION FOR THE UNITED STATES DEPARTMENT OF ENERGY

\section{MASTER}

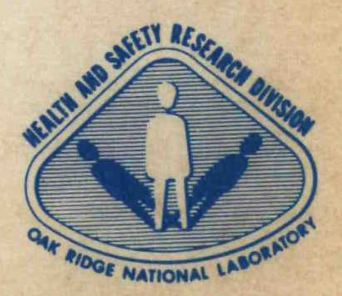

OISTAIBUTEM OF THIS OOCHNEET IS UHUIMTEG 


\title{
DO NOT MICROFILM THIS PAGE
}

\author{
Printed in the United States of America. Available from \\ National Technical Information Service \\ U.S. Department of Commerce \\ 5285 Port Royal Road, Springfield, Virginia 22161 \\ NTIS price codes-Printed Copy: A04; Microfiche A01
}

This report was prepared as an account of work sponsored by an agency of the United States Government. Neither the United States Government nor any agency thereof, nor any of their employees, makes any warranty, express or implied, or assumes any legal liability or responsibility for the accuracy, completeness, or usefulness of any information, apparatus, product, or process disclosed, or represents that its use would not infringe privately owned rights. Reference herein to any specific commercial product, process, or service by trade name, trademark, manufacturer, or otherwise, does not necessarily constitute or imply its endorsement, recommendation, or favoring by the United States Government or any agency thereof. The views and opinions of authors expressed herein do not necessarily state or reflect those of the United States Government or any agency thereof. 


\section{DISCLAIMER}

This report was prepared as an account of work sponsored by an agency of the United States Government. Neither the United States Government nor any agency Thereof, nor any of their employees, makes any warranty, express or implied, or assumes any legal liability or responsibility for the accuracy, completeness, or usefulness of any information, apparatus, product, or process disclosed, or represents that its use would not infringe privately owned rights. Reference herein to any specific commercial product, process, or service by trade name, trademark, manufacturer, or otherwise does not necessarily constitute or imply its endorsement, recommendation, or favoring by the United States Government or any agency thereof. The views and opinions of authors expressed herein do not necessarily state or reflect those of the United States Government or any agency thereof. 


\section{DISCLAIMER}

Portions of this document may be illegible in electronic image products. Images are produced from the best available original document. 


\section{DISCLAMER}

This report was prepared as an account of work sponsored by an agency of the United States Government. Neither the United States Government nor any agency thereof, nor any of their employees, makes any warranty, express or implied, or assumes any legal liability or responsibility for the accuracy, completeness, or usefulness of any information, apparatus, product, or process disclosed, or represents that its use would not infringe privately owned rights. Reference herein to any specific commercial product, process, or service by trade name, trademark, manufacturer, or otherwise does not necessarily constitute or imply its endorsement, recommendation, or favoring by the United States Government or any agency thereof. The views and opinions of authors expressed herein do not necessarily state or reflect those of the United States Government or any agency thereof.
ORNL-5819

Dist. Category UC-41,11

Hesth and Safety Research Division

\section{AN ALGORITHM FOR COMPUTING SIGNIFICANCE LEVES USING THE KOLMOGOROV-SMIRNOV STATISTIC AND VALID FOR BOTR LARGE AND SMALL SAMPLES}

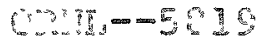

$-20,001505$
S. E. Kurtz

D. E. Fields

* Spring Arbor College, Spring Arbor, Michigan 49283

Date Published - October 1983

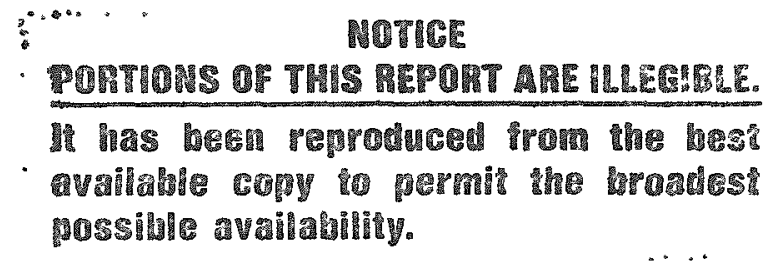

Prepared by the

Oak Ridge National Laboratory

Oak Ridge, Tennessee 37830

operated by

UNION CARBIDE CORPORATION

for the

Office of Defense Waste and Byproducts Management

U.S. DEPARTMENT OF ENERGY

Under Contract No. W-7405-eng-26 
iii $\|^{\circ}$

CONTENTS

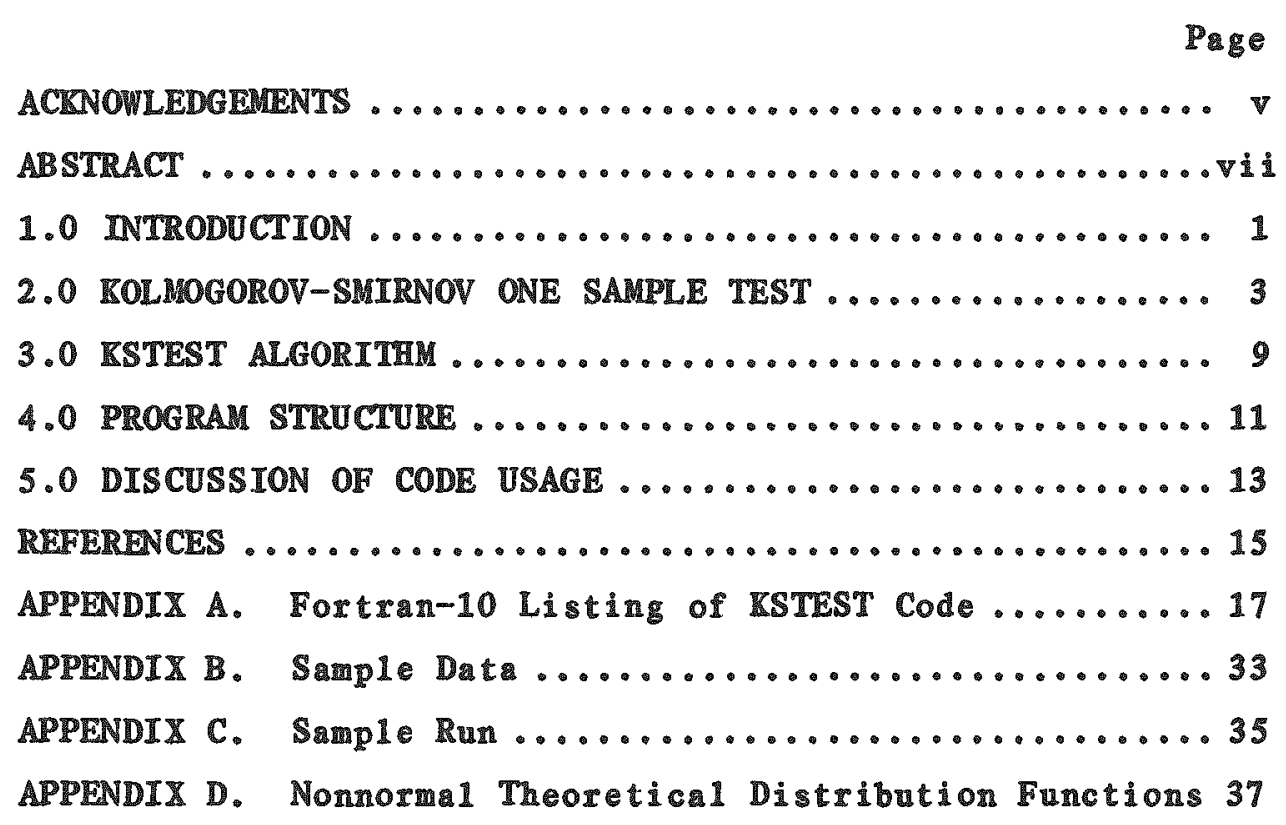


:

. 


\section{ACKNOWLEDGEMENTS}

The authors wish to thank $S$. R. Glandon for his frequent advice and assistance in the use of the various ORNL computer systems which were used in the development of the code. Thanks are also extended to C. W. Miller and M. Cristy for their review of the manuscript and to Shirley Norman for helping with manuscript preparation. Portions of this work were sponsored by the Office of Defense Waste and Byproducts Management. United States Department of Energy, under the Development of Low Leve1 Waste Disposa1 Facilities task. FTPA \# ONL-WN13 and Activity \# AR 051005 I. 
The RSTEST code presented here is designed to perform the KolmogorovSmirnov one-sample test. The code may be used as a stand-alone program or the principal subroutines may be excerpted and used to service other programs.

The Rolmogorov-Smirnov one-sample test is a nonparametric goodnessof-it test. A number of codes to perform this test are in existence, but they suffer from the inability to provide meaningful results in the case of small sample sizes (number of values 580 ). The ISTEST code overcomes this inadequacy by using two distinct algorithms. If the sample size is greater than 80, an asymptotic series developed by Smirnov is evaluated. If the sample size is 80 or less. a table of values generated by Birnbau is referenced. Valid results can be obtained from ISTEST when the sample contains from 3 to 300 data points.

The program was developed on Digital Equipment Corporation PDP-10 computer using the FORTRAN-10 languge. The code size is approzimately 450 card images and the typical CPU execution time is $0.19 \mathrm{~s}$. 


\section{INTRODUCTION}

The Rolmogorov-Smirnov (X-S) one sample, two-sided test is aseful. yet infrequently used, statistical test. It is a nonparametric goodness-of-fit test: that is, the test is a measure of how well two probability distribution functions match one another, independent of the statistical distributions of the data being compared. There are several possible applications of the Rolmogorov-Smirnov test, but the most common application, which will be discussed in this paper, is the compaxison of an empirical probability distribution of a set of data with an assuned theoretical probability distribution. The $\mathbb{R}-S$ test has the advantage over the most common goodness-of-fit test, the $X^{2}$ test, in that the $\mathbb{K}-S$ test treats the data individualy rather than in groups. It may be considered to be, in general, the more powerful of the two Lests (Siege1, 1956).

The $\mathrm{F}-\mathrm{S}$ test may have applications wherever a goodness-of-fit test is required. It has, for example, been applied in the computer code TERPED/P (Glandon and Fields, 1982), code which determines whether a set of data may be considered to be distributed normally or $10 \mathrm{~g}-$ normally. Such an application can be very useful for the evaluation and assessment of environental impacts and the output of mathematical models (Fie1ds, 1981).

The original telease of the TERPED/P code used IMSL" subroutines for the evaluation of the K-S test. This approach had the drawback that the IMSL routines give valid results only when $N \geq 80$, where $N$ is the number of date points. NAG subroutines and SAS are somewhat superior in this regard, having 1 ower 1 imits of $\mathrm{N}=35$ and $\mathrm{N}=50$, respectively. The methodology we have developed is valid for $N>3$ data points.

- International Mathematical and Statistical Library, Inc.. Houston, Texas.

* Numerical Algoxithms Group. Downers Grove, I11inois.

- Proprietary soltware distributed by SAS Institute. Inc., Raleigh, North Carolina. 
This work is an outgrowth of an attempt to increase the usefulness of the TERPED/P code by overcoming the $N \geq 80$ constraint imposed by the IMSL subrontines.

The KSTEST code which we have developed is a stand-alone program package for the performance of the Kolmogorov-Smirnov one-sample test. The program has been constructed so that the user may invoke the code directly to perform the $\mathbb{K}-S$ test or my excerpt the principle subroutines for use in other programs. These subroutines have already been applied as a section of the TERPED computer code (Kurtz and Fields, in press). The TERPED code may be used to examine the statistical distribution of a data set and plot the data set. 


\section{KOLMOGOROV-SMIRNOV OVE SAMPLE TEST}

The $\mathbb{K}-S$ one sample, two-sided test is a measure of the goodness of fit between the cumulative probability distribution of a set of data and an assuned theoretical cunulative probability distribution. The $\mathbb{R}-\mathbb{S}$ statistic, $\mathbb{D}_{N}$, on which the test is based, is the maximun difference between corresponding terms of the two distributions. The statistic is independent of the distributions themselves, being instead a function of N, the size of the data sample. Associated with the statistic and the value of $N$ there is anique probability level. This value is the probability that the difference $D_{N}$ is due to random chance rather than a genuine difference between the distributions. Hence, the number (ono minus the probability) is the significance level, a, at which one may say the two distributions are the same.

Consider a random variable $\mathbb{X}$ with the continuous distribution function $F(x)$ defined as the probability that $X$ is less than or equal to some value $\mathbb{x}$. That is.

$$
F(x)=P(X \leq x)
$$

Given that $\mathbb{X}_{1}, \mathbb{X}_{2}, \cdots \mathbb{X}_{\mathbb{N}}$ is sample of $X$ of size $\mathbb{N}$ such that

$$
\mathrm{x}_{1} \leq \mathrm{x}_{2} \leq \cdots \leq \mathrm{x}_{N}
$$

the emplical probability distribution function $F_{N}(x)$ is usually defined by

$$
F_{N}(x)= \begin{cases}0 & x<\mathbb{X}_{1} \\ i / N & x_{i} \leq x \leq X_{i+1} \quad i=1,2, \ldots, N-1 \\ 1 & X_{N} \leq x\end{cases}
$$

This cumlative distribution is a step function of height $1 / \mathbb{N}$ with $\mathbb{N}$ steps. When the distribution under consideration is normal, its cumbiative probability is more ccurately given by $\mathbb{F}_{N}(x)=(i-3 / 8) /(\mathbb{N}+1 / 4)$ in the range $\mathbb{X}_{i} \leq x \leq \mathbb{x}_{i+1}, i=1,2, \ldots, N-1$ and 0 or 1 el sewhere (Kimba11, 
1960). We have used this definition for the particular case of normal distribution.

The Kolmogorov-Smirnov statistic is now defined s

$$
\mathbb{D}_{N}=\max \left|F(x)-F_{N}(x)\right| \quad x=x_{1}, x_{2}, \cdots x_{N}
$$

In his original work Kolmogorov found that the distribution of $D_{N}$ was dependent on $N$ but independent of $F(x)$. He also derived formulas for determining the probability associated with the value of $D_{N}$ (Rolmogorov, 1933).

In the general case, for ample of any size the probability is given in form involving a recursive definition. If $c$ is some integer less than $N$, where $N$ is the sample size, the probability associated with a paxticular value of $D_{\mathbb{N}}$ is given by

$$
P\left(D_{N}<\frac{c}{N}\right)=\frac{N !}{N^{N}} e^{N} R_{0, N}(c) .
$$

$\mathbb{R}_{i, k}(c)$ is defined for $i$ any integer, $k$ any positive integer, and $c$ any positive integer less than or equal to $\mathrm{N}_{\text {s }}$ and is given by

$$
\begin{array}{ll}
\mathbb{R}_{0,0}(c)=1, \quad \mathbf{R}_{i, 0}(c)=0 & i \neq 0 \\
\mathbb{R}_{i, k}(c)=0 & \text { i } \geq c \\
\mathbb{R}_{i, k+1}(c)=\frac{1}{e} \sum_{s=0}^{2 c-1} R_{i+1-s, k}(c) \frac{1}{s !} & \text { i } \leq c-1 .
\end{array}
$$

A table of values of $P\left(D_{N}<c / n\right)$ for $N=1(1) 100$ and $c=\min (N, 15)$ (1) has been computed by Birnbam and has been used as a part of the computational algorithm (Birnbaum, 1952).

The recursive definition above tends to become quite cumbersome even for small values of $\mathbb{N}$. To avoid the computational problems inherent in that method. Kolmogorov derived an asymptotic relation for 
the probability in the limit as $N$ approaches infinity. This relation is expressed as

$$
\left.L(z)=\underset{N=\infty}{\operatorname{iim}_{N} P\left(D_{N}\right.}<\frac{\underline{z}}{N}\right)=1-2 \sum_{k=1}^{\infty}(-1)^{k-1} e^{-2 k^{2} z^{2}}
$$

where $z=\mathbb{D}_{\mathbb{N}} \sqrt{N_{0}}$ An equivalent form is found to be

$$
L(z)=\frac{\sqrt{2 \pi}}{z} \sum_{k=1}^{\infty} \exp \left(-(2 k-1)^{2} \pi^{2} / 8 z^{2}\right)
$$

Which is more useful for small 2 . Both of these series have the advantage of very rapid convergence - thre terms are usually sufficient. The condition that $N$ approaches infinity, however, makes them unstisfactory for small values of $\mathrm{N}$ with the cutof point frequently being placed around $N=80$. $L(z)$ has been tabulated from $z=0.28$ to $z=3.00$ (Smirnov, 1948).

The first step in the computation of probability levels is to obtain the statistic $\mathbb{D}_{N^{*}}$ When the continnous cumulative probability of the theoretical distribution is plotted together with the step function of the empirical distribution, the role of $\mathbb{D}_{\mathrm{N}}$ becomes graphically clear (Fig. 1).

The endpoints of each line segment are determined by adjacent values of $X$, the data, and the step size is $1 / N$. The difference between the two distributions are simply the distances from the ends of the 1 ine segments to the curve itself. The maximum difference, $\mathbb{D}_{N^{*}}$ is the maximum distance. Clearly two values of the step function must be examined for each data point since the step function suffers both a left-handed and a right-handed discontinuity. Procedurally the approach is to calculate the ordinate of the theoretical distribution at each data point then determine the difference between this ordinate and the ordinates of the two steps of the empirical distribution. one on either side.

Since the differences are calculated at corresponding points of the two distributions, care must be taken in the evaluation of tied data points to insure that the correct ordinates are used. Tied dat values may be thought of as line segments of widh zero, appearing graphically as steps of $s i z e \mathrm{~m} / \mathrm{N}$ where $m$ is the number of times the value is 
ORNL-DWC 3C-12127

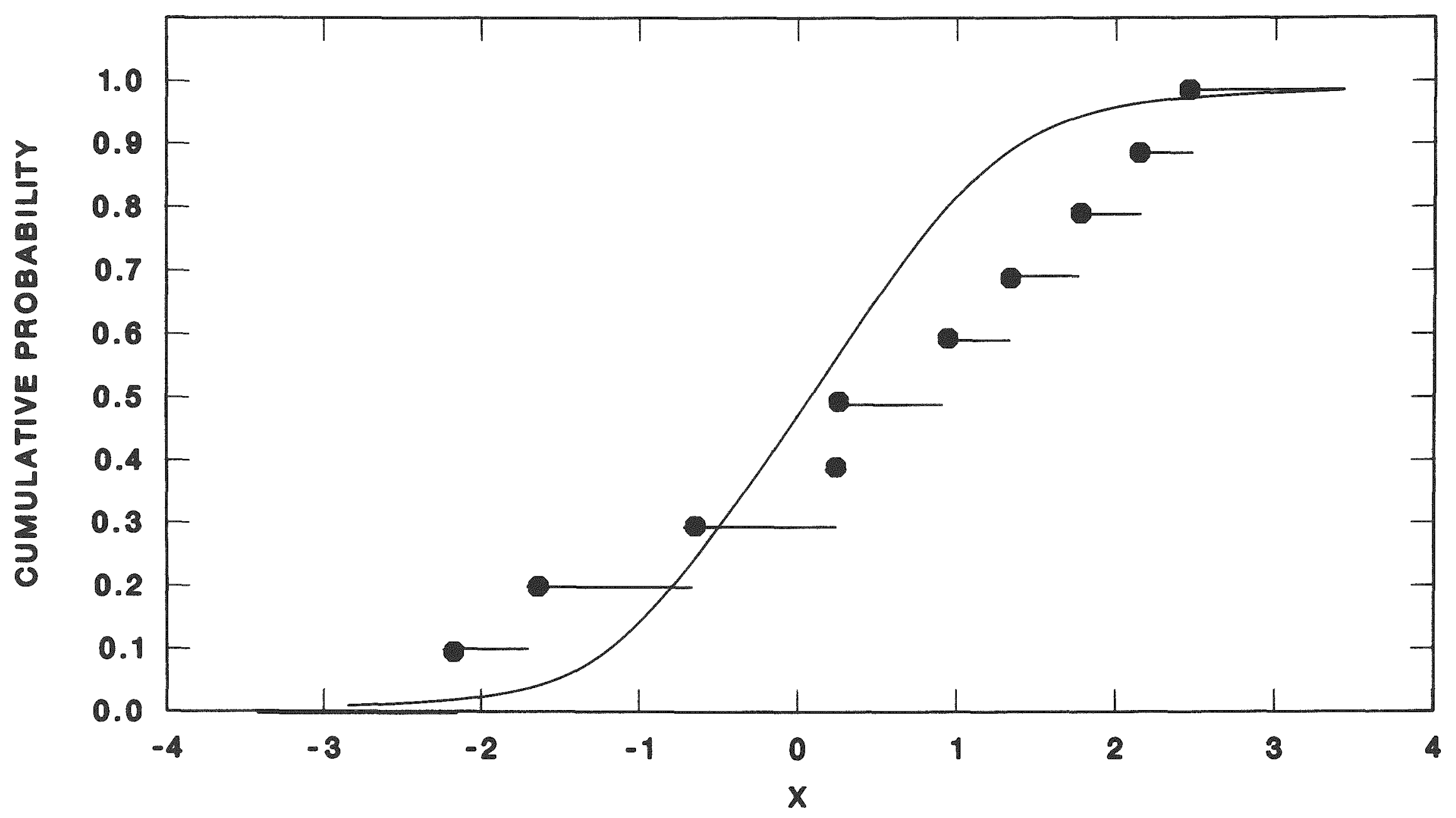

Figure 1. This figure shows the determination of the statistic $D_{\mathbb{N}}$ from the difference between corresponding data and fitted values. 
repeated. For example, in Fig. 1 the value 0.2 occurs twice and appears as a step of size 2/10. In the case of multiple tied data points, the right-and left-handed differences need not be calculated for each repeated values - once for each side is sufficient. However, since the cumulative probability of the empirical distribution continues to increase while the data values remain constant, the left-handed difference must be computed using the ordinate of the first tied value while the right-handed difference must be computed using the ordinate of the final tied value. The ordinate of the theoretical distribution is the same in either case.

After the statistic is found, the associated probability may be determined. In the case of $\operatorname{smal1} \mathrm{N}, \mathrm{N} \leq 80$, the probability may be found from Kolmogorov's original formulation involving the recursive definition: $D_{\mathbb{N}}$ is characterized as $\mathrm{c} / \mathrm{N}$ where the smallest positive integer value for $c$ is chosen such that $D_{N}<c / N$. Application of the recursive definition for $\mathbb{R}_{i, k}$ with parameter c then provides the value of $\mathbb{R}_{0, N}(c)$ which may be substituted into Kolmogorov's equation to obtain the probability.

If the value of $\mathrm{N}$ is large, $\mathrm{N}>80$, it may be desirable to use one of the asymptotic relations. This is done by forming the weighted statistic $z=D_{N} \sqrt{N}$ and selecting the appropriate series based on the value of z. The sumation will give the probability, $L(z)$.

Additional methodologies for calculating the value of the $\mathbb{K}-\mathrm{S}$ statistics and its associated probability have been developed and a number of them are summarized by Pomeranz (Pomeranz, 1973). 


\section{KSTEST ALCORITHM}

For computational purposes the algorithm used by the ESTEST code varies sightly from the procedure outlined in the preceding section.

For the case of $\mathrm{N} \leq 80$ the table of probabilities generated by Birnbaum has been used to avoid the recursive calculation of the values of $\mathbb{R}_{i, k}(c)$. At even moderate values of $N$, avoidance of the recursive calculation is almost essential since the number of terms generated by the recursive definition increases as $\mathrm{N}^{3}$. By using the tabulated values of the probabilities, we have avoided using Kolmogorov's equation at all and, hence, need not concern ourselves with the computation of $\mathbb{R}_{0, N}(c)$.

Birnban's table gives probabilities for $D_{N}$ parameterized by various values of $c$ and $N$. Our method is to compute the statistic and then ind integer values $c_{1}$ and $c_{2}$ such that

$$
\frac{c_{1}}{N} \leq D_{N} \leq \frac{c_{2}}{N}
$$

Probabilities corresponding to these values of $c_{1} / \mathrm{N}$ and $c_{2} / \mathrm{N}$ are then obtained from the table and adjusted by linear interpolation. Probabilities in the table are given to five decimal places and error analys of the computational methods used in its generation indicates that 21 five digits axe significant (Birnbaum, 1952).

For the case of $N>80$, the alternative approach of the asymptotic series is used. The weighted statistic, $z=D_{N} \sqrt{N_{1}}$ is formed and based on its size the appropriate form of the series is selected. $z=0.80$ is used as the transition value between the two series.

It is of interest to consider why $N=80$ was chosen as the transition between the Birmbarm method and the asymptotic series approach. Although Birnbaum's table goes to $N=100$, it was decided to use only the portion for which $\mathrm{N} \leq 80$. This value was chosen for two reasons. First, whereas the values in the table are accurate to five places, the table itself is incomplete. To maintain five digit accuracy for all characterizations of $D_{N}$ would have required values of cranging from 1 to approximately $4 \sqrt{N}$. This implies an upper value of $c=35$ for $N=80$ and $c=40$ for $N=100$. Birnbaun's table stops at $c=15$, however. The 
discrepancy between $c=15$ and $c=35$ does cause some exror at $N=80$ and below, but this was not deemed worthy of concern - the worst case relative error being approximately $0.62 \%$. The discrepancy between $c=15$ and $c=40$ in the region of $80<N \leq 100$ was found to be more significant, how ever. Worst case relative errors ranged from $0.66 \%$ to $1.98 \%$, so this section of the table was onitted.

The second justification for the asymptotic series for $N>80$ is that both methods - interpolation of the table and summation of the series give comparable results in the immediate vicinity of $\mathrm{N}=80$. So long as $\mathrm{D}_{\mathrm{N}}$ is not chacterized by a c value close to the upper limits of the table, the tabular method gives more accurate results.

For all but the smallest values of $c$, the asymptotic method gives good agrement even for $80<\mathrm{N} \leq 100$. However, in the case of sma11 c, resulting from a small value for $D_{N}$, the asymptotic method can give poor resulis, a weakness shared by the IMSL routine for performing the $\mathbb{K}-S$ test. Relative errors can become as large as several hundred percent. Little benefit can be gained by extending the use of the table to $\mathrm{N}=100$ since the poor performance of the asymptotic method at small $\mathrm{c}$ is not significantiy better in the vicinity of $N=100$ than in the vicinity of $\mathrm{N}=80$.

In the region of $80<N<100$ the user may wish to consult Birnbaum's able if $D_{N} \leq 4 / N$. 


\section{PROGRAM STRUCTURE}

The subprogram structure of the ISTEST code is shown in Fig. 2 . The code consists of a main program and seven subprograms which perform the actual computations of the statistical parameters. A FORTRAN-10 1 isting of the code is given in Appendis A.

The Main Program structures flow of control. accepts data and control information from the user and outputs the computed values. Subroutine SISORT performs a straight-insertion sort of the data values, arranging them into scending order. SANDM calculates the sample mean and standard deviation of the data set. Subroutine NSS calculates the K-S statistic after calling DSNORM which computes the normalized cumulative probability of the theoretical distribution. DSNORM is the probability distribution function generation subroutine which may be designated by the user and which gives the form of the theoretical cumulative probability distribution. In this case we have assumed normal distribution and hence have added the NAG routine ERF which is called by DSNORM and calculates values of the error function. 


\section{DISCUSSION OF CODE USAGE}

KSTEST is an interactive code: a sample run showing the computeruser dialogue is reproduced in Appendiz $C$.

Upon involing the code, the user first specifies the method of data entry - by hand or from a data file. If file input is specified, file number is requested. Regardless of the method of input, the number of values to be read is requested, followed by query on the arrangement of the data. A negative response, indicating that the data are not ordered, ill cause subroutine SISORT to be invoked. Once data inpat is complete, computations are begun and control does not return to the user until their completion, whereupon it is possible to select a listing of the ordered data. Finaly, values of the calculated parameters are printed and the program is terminated or restarted at the user's discretion.

ISTEST performs number of checks on user-supplied values and select calculated values and prints appropriate warnings. All control information submitted by the user is checked for correct form. If an input value is not in the correct form. the program prints warning and awaits 2 vid response.

The progran also checks the size of the data set. A warning is printed if there are more than 300 points. If hand input was specified, the program then repeats its request for the number of data points. If file input was specified with more than 300 points to be read, the same message is printed and a new response is awaited. If ail points in the file are to be read, the progran attempts to read 300 values. If the full 300 are read, warning is issued and execution proceeds.

The 300 value 1 imit may be modified by changing four lines in the main program. These statements are the data array DIMENSION statement and the three logical IF statements which check the size of the sample.

The RSTEST code is a stand-alone program package for the execution of the Kolmogorov-Smirnov one sample test. Care has been taken in the development of the code so that the principle subroutines re readily withdrawn for use in existing programs. 
The subroutines which perform the actual computations for the $\mathbb{Z}-\mathbb{S}$ test are NKS and DSNORM, long with the real function ERF, NLE80 and NGT80. NKS is the cal1ing subprogram for all of the other subroutines.

To excerpt these subroutines for use in an existing program. it will be necessary for the calling program (which will call NKS) to define the following items: the sorted data array, the length of this array, the variables to be used for the statistic $D_{N}$, and the significance level a. In adition, the sample mean and standard deviation have been passed to DSNORM through COMMON. The prospective user will need to pass these values as subroutine arguments for NRS and DSNORM or adjust COMMON storage appropriately.

The subroutine SANDM for calculating the mean and standard deviation and SISORT for oxdering the data have not been included among the routines essential to the test. Many programs which might use the $\mathrm{E}-\mathrm{S}$ test may already have provisions for these tasks. If desired, both SANDM and SISORT may be carried over intact with the other routines. Some discretion should be used regarding the SKSORT subroutine, however. SISORT arranges the sample data into ascending order by means of a straight insertion sort. This sorting algorithm is not highly efficient. If large data sets are to be evaluated, the user may wish to adopt different sorting algorithm.

When the core of principal subroutines is used to service another progran, the theoretical probability distribution subroutine DSNORM must be specified in the user's main program by means of an EXTERNAL statement. Further flexibility is avalable to the user by modifying DSNORM to calculate some distribution function other than normal. Several such possibilities and the requisite coding changes are given in Appendiz D. If the user selects a distribution other than normal, some slight modifications should 1 so be made to subroutine NKS. NKS calculates the cumulative probabilities of the empirical distribution based on the asumption that it is normal distribution. Because of this assumption. mentioned in Sect. 2. NKS uses the modified formula for the cumu12tive probability due to Kimbal1. If the user selects a nonnormal distribution, two lines of code will need to be changed in the NKS subprogram. These changes are also outiined in Appendix D. 
REFERENCES

Birnbaum, Z. W., 1952. "Numerical Tabulation of the Distribution of Kolmogorov"s Statistic for Finite Sample Size," American Statistical Assm. Jourma1. 47, p. 425 .

Fie1ds, D. F., 1981. TERPED: A Versatile Code for Examining the Distribution of Experimenta1 Data, ORNL-5689, Oak Ridge National Laboratory, Oak Ridge, Tennessee.

G1andon, S. R. and Fields, D. E., 1982. An Interactive Statistica1 Distribution Analysis Program Utilizing Numerical and Graphical Methods. ORNL-5813, Oak Ridge Nationa1 Laboratory, Oak Ridge, Tennessee.

Kimba11, B. F., 1960. "On the Choice of Plotting Positions on Probability Paper." American Statistical Assm. Journal, 55, p. 546.

Furtz, S.E. and Fields, D. E. An Anglysis/Plot Generation Code with Simificance Levels Computed Using Kolmogorov-Smirnov Statistics Valid for Both Large and Sma11 Samples, (in press), ORNL-5967, Oak Ridge National Laboratory, Oak Ridge, Tennessee.

Pomeranz, J. E, 1973. Exact Values of the Two-Sided rolmogorov-Sairnov Cumuletive Distribution for Finite Sample Size, CSD TR 88, Purdue University, Lafayette, Indiana.

Siege1. S., 1956. Nonparametric Statistics for the Behavioral Science. MoGraw-Hi11. New York, New York.

Smirnov, N., 1948. "Table for Estimating the Goodness of Fit at Empirical Distributions," Anna1s of Mathematical Statistics, 19, p. 279. 
APPENDIX A. FORTRAN-10 LISTING OF ISTEST CODE

The ISTEST code executes on the DRC PDP-10 computer. The only utility required is the NAG real function ERF for the evalution of the exror iunction. 
C

C CODE TSTST

\section{ORIGTVI TRS}

C

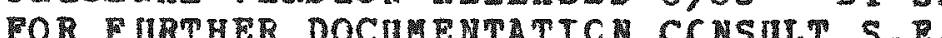

AN $A$ GORTPHA POR CONPUTING SIGNIRICANCE LEVILS USING TIE

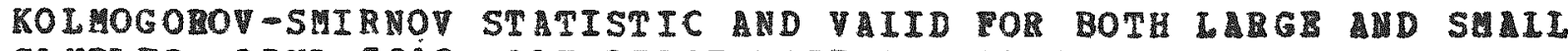

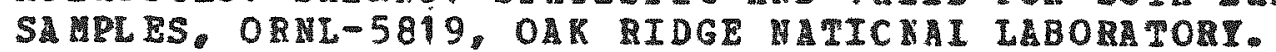

CCM

EXTEENAL DSNCEM

DATE II.E/HAND, FIID'

WR: $5(5,1$ (A)

1 1)

จED $(5,12,1)$

IF(A.NE, F) GOTO 2.

WTE

SAD $(5,1401) \mathrm{MIN}$

GOTO 41

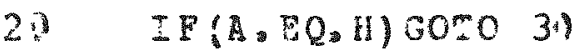

W 1 I $3: 5,15,4)$

$30=011$

3 ก $\quad y N=I M$

4) WEITE $(5,1690)$

WITE $(5,1700)$

READ $(5,18$ กी

IF(N.IE. 2) 60.05

WRIIE $(5.19010)$

51) WITE:5,2010)

$?$ EAD $(5,120 \mathrm{M})$

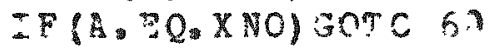

IF (A. FQ. IES) GC:C 5 )

WRITE $(5,1500)$

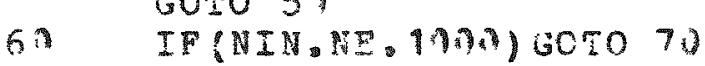

W.TE: $: 5,2$ In)

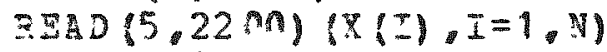

Gro 1 


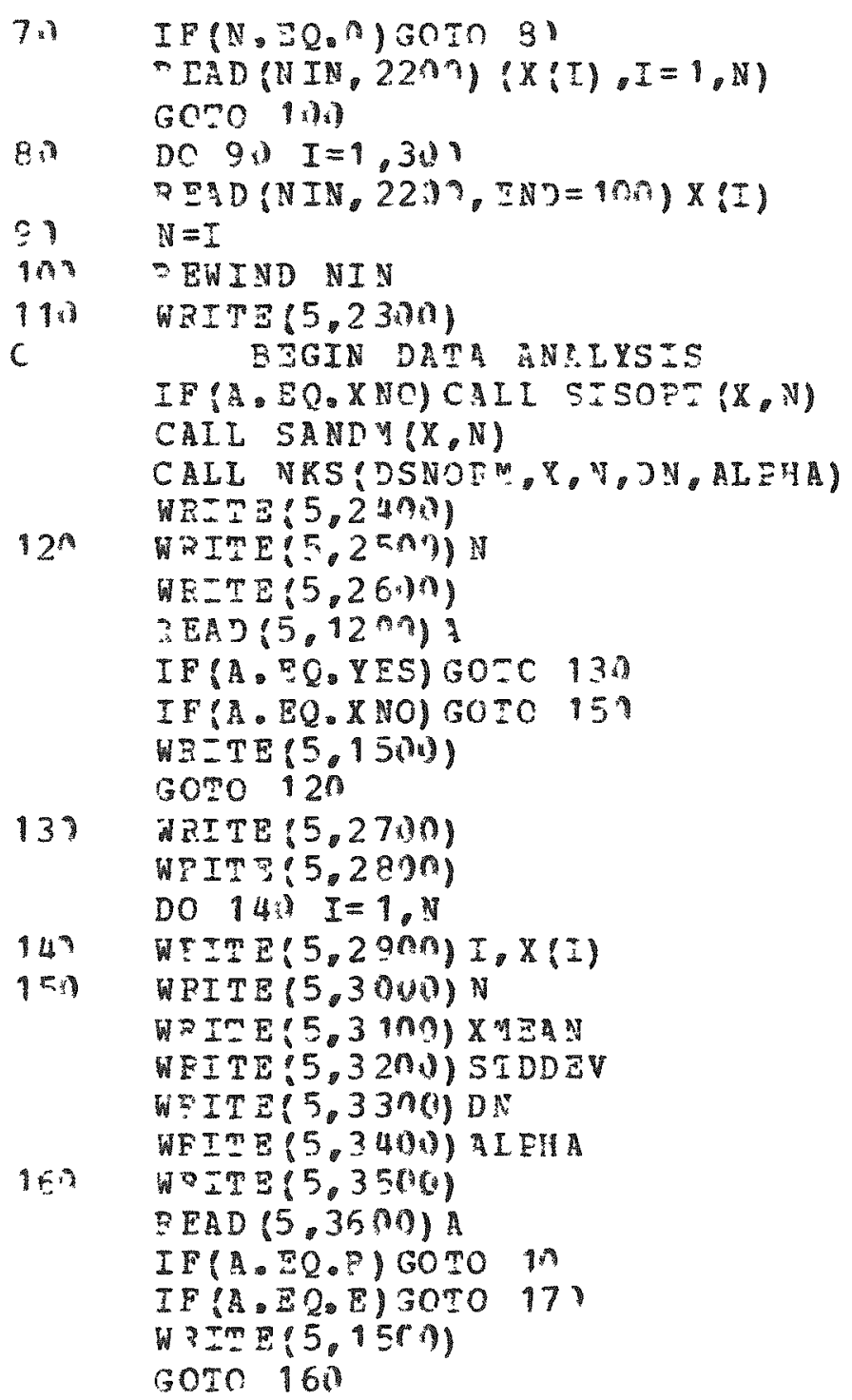




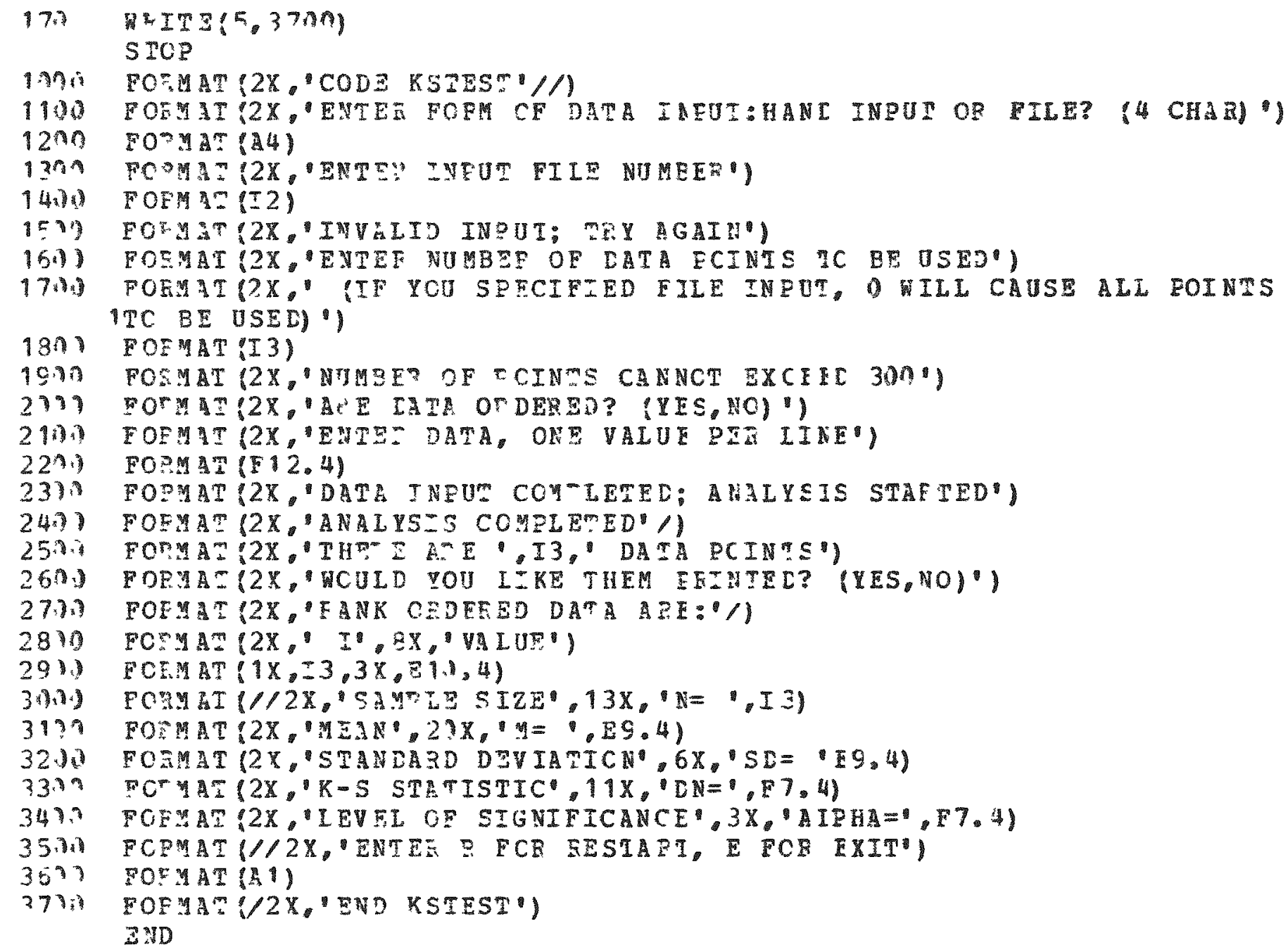




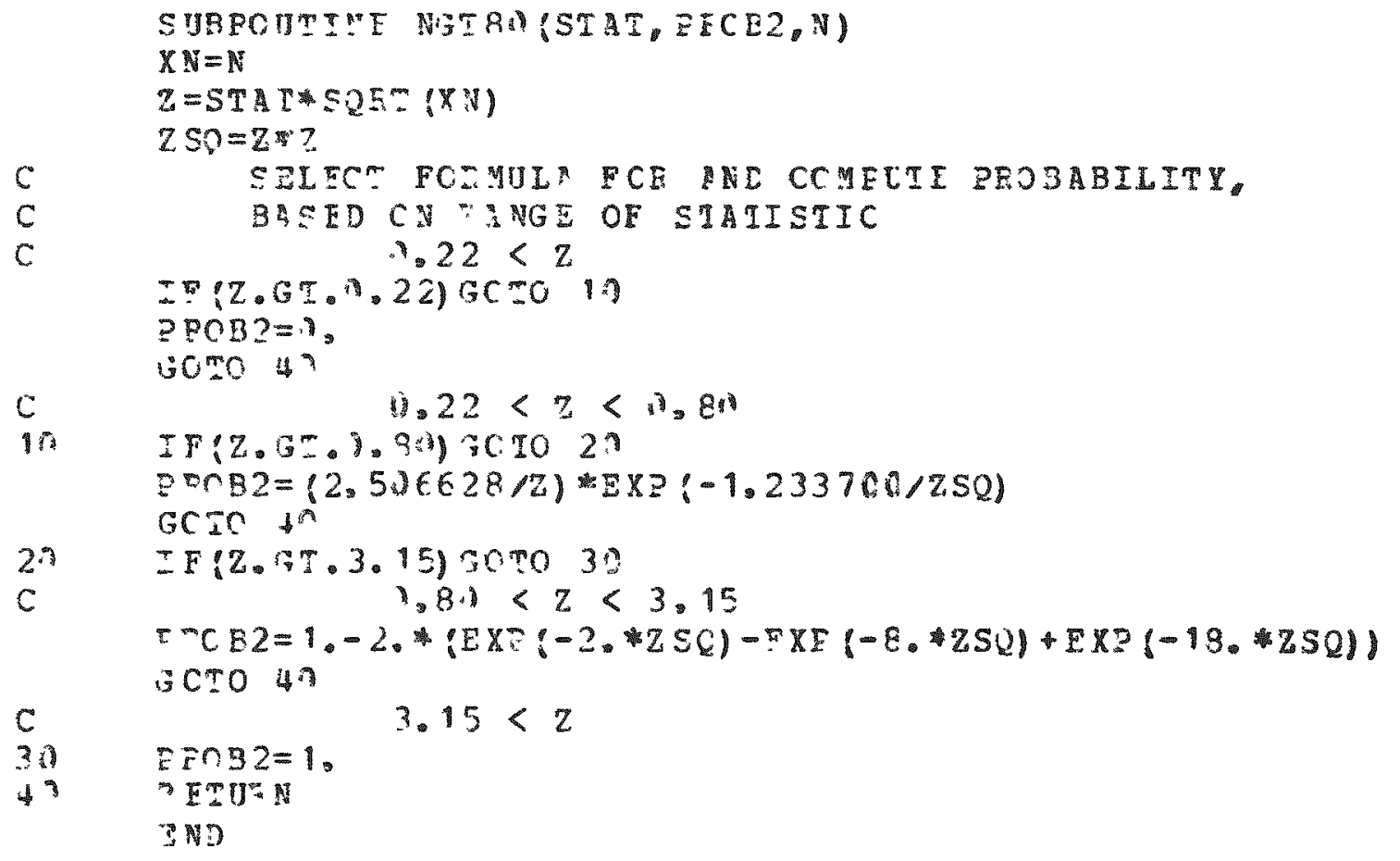




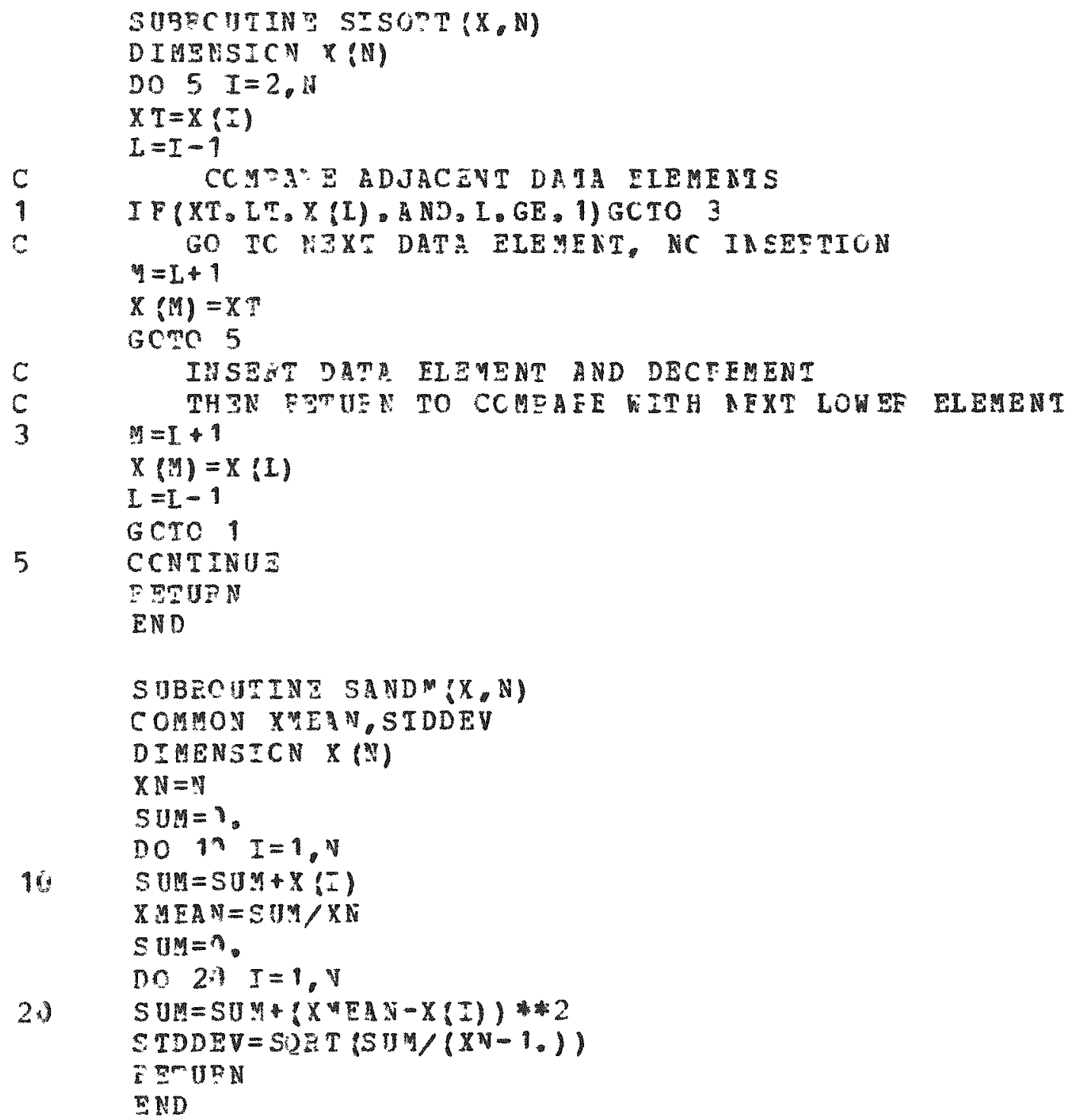




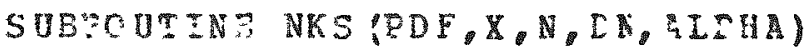

DIMENSECN X:M)

C

IMITI:LIZT VA-IABIES

EDE $1=h$.

EDF 2 =

$D N=9$.

$\mathrm{X} N=\mathbb{N}$

$X N=X N+25$

$1.1 \quad I=1$

$2^{3} \quad \mathrm{~J}=\mathrm{I}$

CHECK FCE TIED DAT VALUES

3. IF:X(I).Im.X(I+1))GCTC $4 C$

$I=I+1$

I. (I. EQ. N) GCRO 4.

Gnom $3 \mathrm{n}$

4.7 $\quad X I=I$

$X J=J$

c

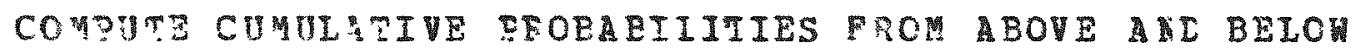

$E D F 1=(\mathrm{XJ}-1.375) / \mathrm{T} \mathrm{N}$

EDF $2=(X I-375) / X N$

CALI $2 D F(X(I), F)$

C COMDABE FO

$D N=A M X 1(D N, A B S(F-B D F 1), A E S(E-I I E 2))$

C INCS MENT COUNTEZS AND EICK ICINT CF LOOZ DEENIRY

$I=I+1$

If(I, LT, V) and 2 )

$J=I$

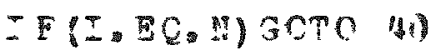

CHCCSE AND CALI FFCBABIEITI SURROUTINE

C IF(N.UT, BH) GOTC 5\%)

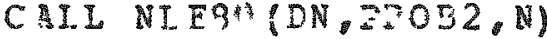

(G) COL 6

51 CBLI NRTQR DN, DOOB2,N)

$61 \quad A L P H A=1,-P$ POB 2

ETU?

END 


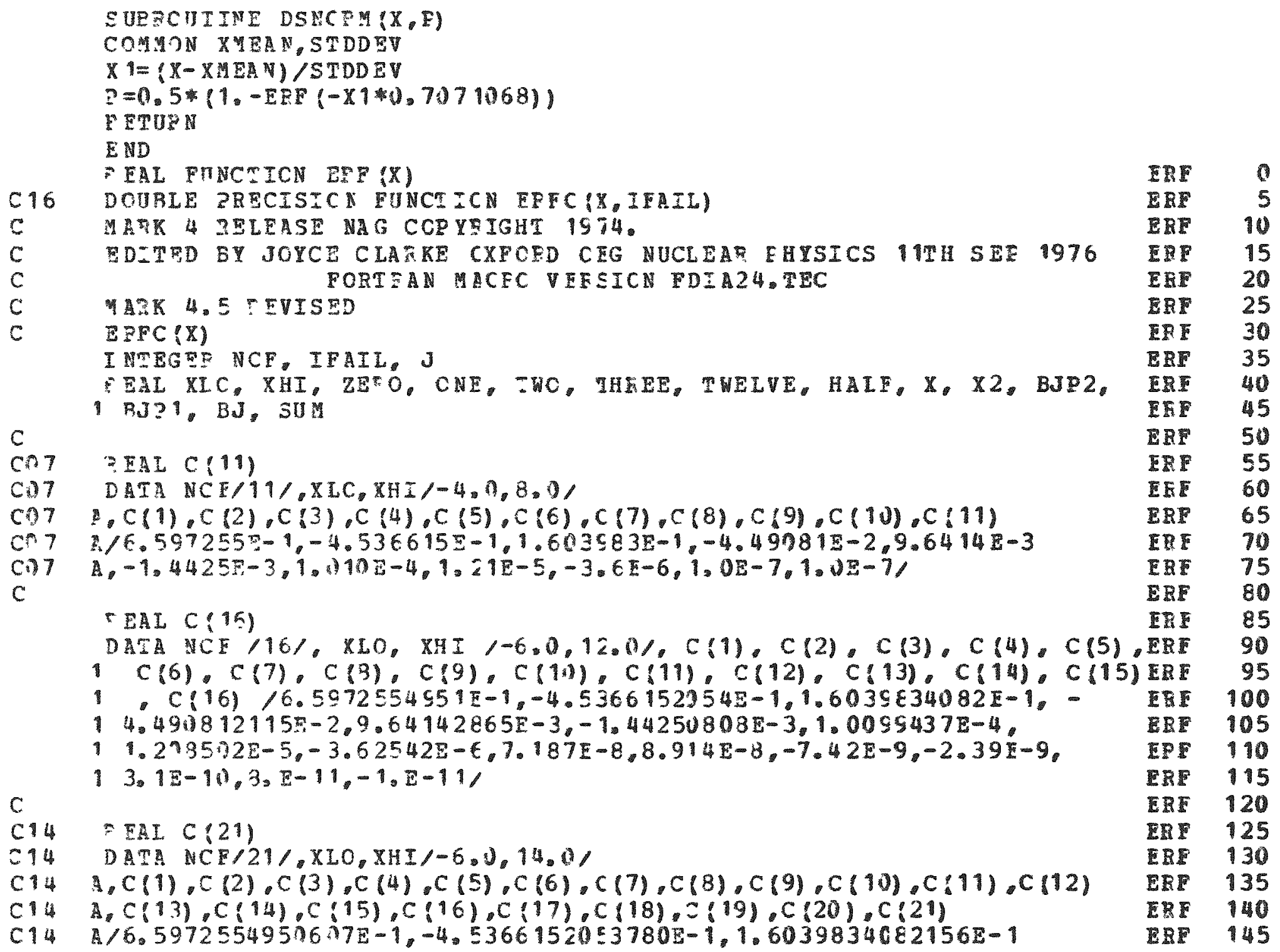


C1 $A,-4.49912115112 g-2,9.64142865070 \mathrm{E}-3,-1.44250807774 \mathrm{E}-3$

C14 $1.0099436735 \mathrm{E}-4,1.2 n 8502453 \mathrm{E}-5,-3.62542060 \mathrm{E}-6.7 .18681 \mathrm{E}-\mathrm{E}$

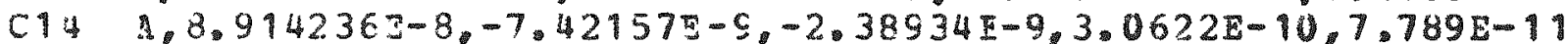

C14 $.-1.197 \mathrm{E}-11,-3.09 \mathrm{~g}-12.3 .5 \mathrm{E}-13,1.4 \mathrm{E}-13,-1.0 \mathrm{E}-14,-1.0 \mathrm{E}-14 \mathrm{~L}$

FEF 155

C

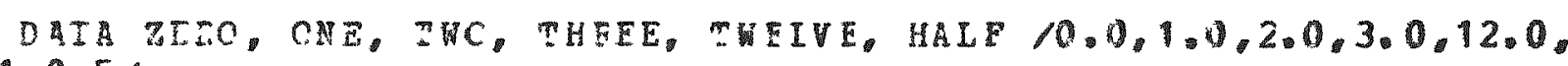

ERE 160

ERF 165 $13.5 /$

c

IF $(X, I E, X I C)$ GC TC 3

IE (X,GE.XYI) GO TO 4 .

c

$X 2=T W C=$ TWELVE/(ABS (X)+HREE)

C SUMATICV

R.JP2 = $2 F: 0$

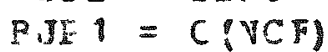

$J=N C F-1$

1n $\mathrm{BI}=\mathrm{X} 2 \mathrm{BJ} \cdot \mathrm{J}-\mathrm{BJ} 22+\mathrm{C}(\mathrm{J})$

IF (I. E2. U) GC TO 20

$B J: 2=$ EITI

$B$ J21 $=B 3$

$J=J-1$

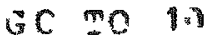

2) $S U$ प $=H A L F *(B]-.B J ? 2) * E X E(-X) X\}$

IF (X.LT.ZEn GC GO 5 .

$E F C=501$ 等

GC TC 61

3 E $E C=$ Tho

GO TO 61

$4^{n} E^{-} F C=2 \Gamma \times$

GO TO 6

50 EFC = IWC - SUM

5.7 $E F=1 .-F C$

EETUEN

END

IRE 170

ERF 175

ERE 180

TEF 185

ERE 190

ERE 195

EEF 200

ERF 205

ERE 210

ERF 215

ERE 220

IFE 225

ERT 230

IR 235

IRE 240

ERF 245

ED 250

IRE 255

ERT 260

II 265

E2F 270

ERT 275

IRE 280

ERE 285

EEP 290

ER 295

ER 300

ERE 305

ED 310

ERP 315 


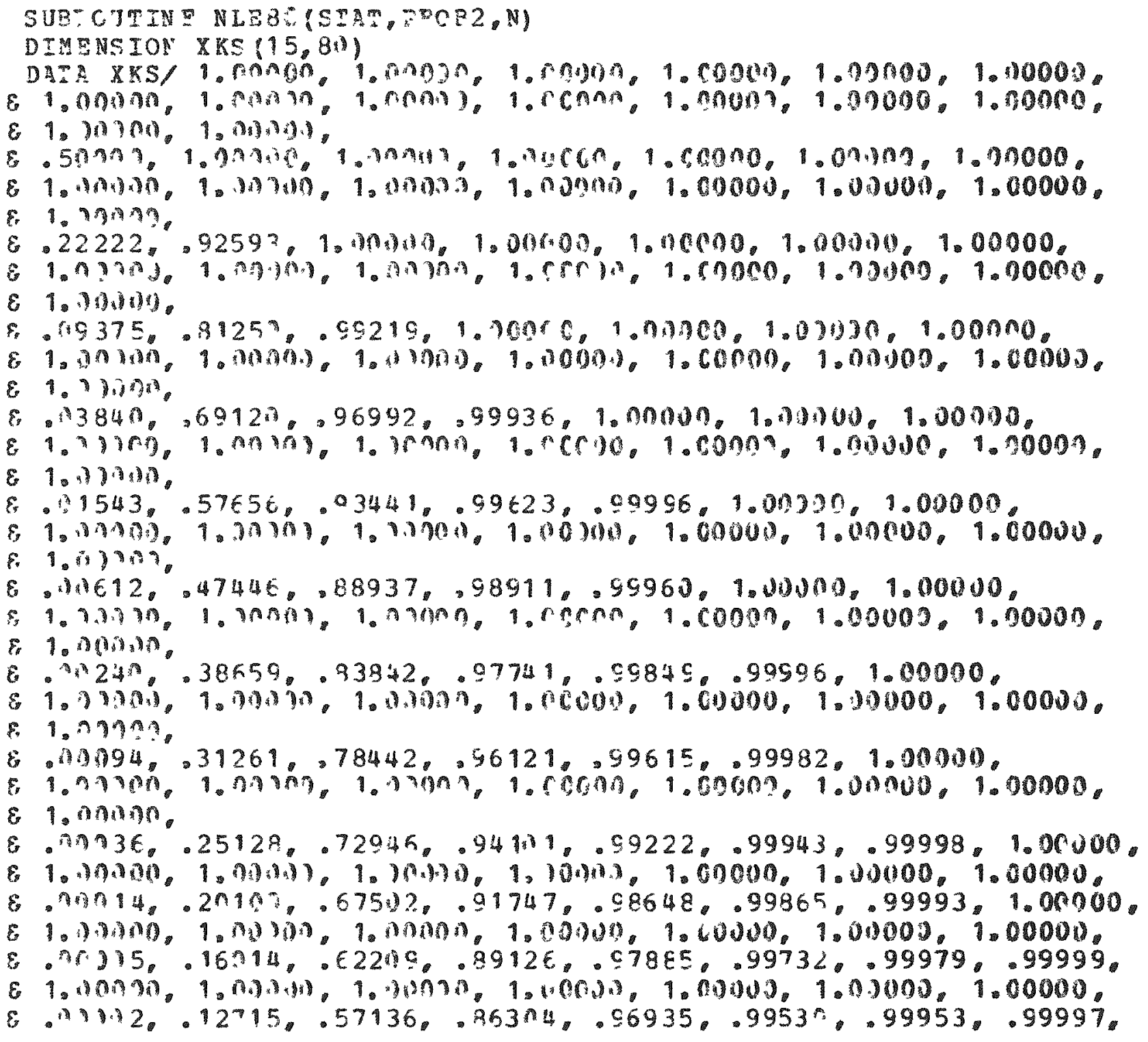




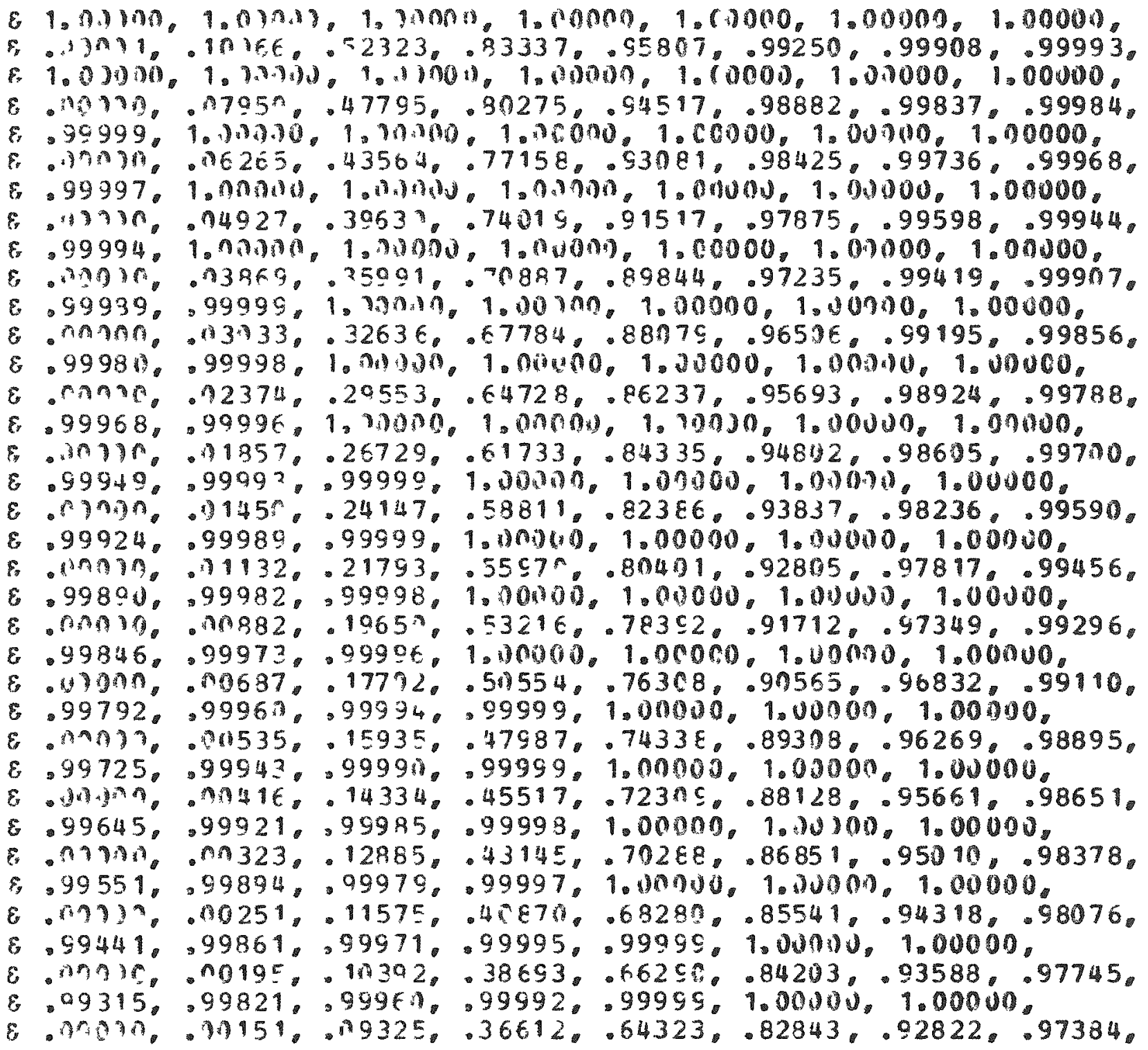




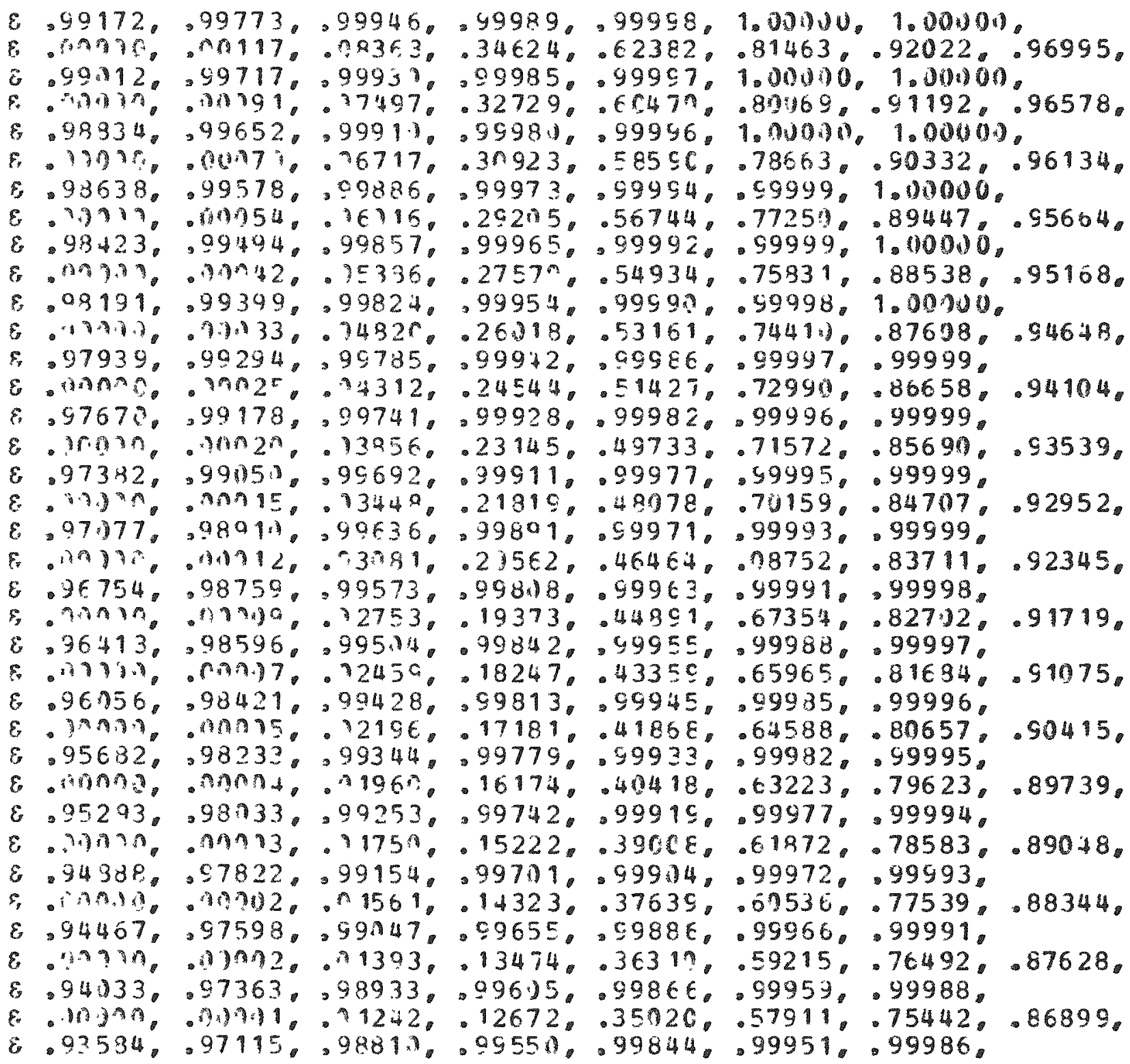




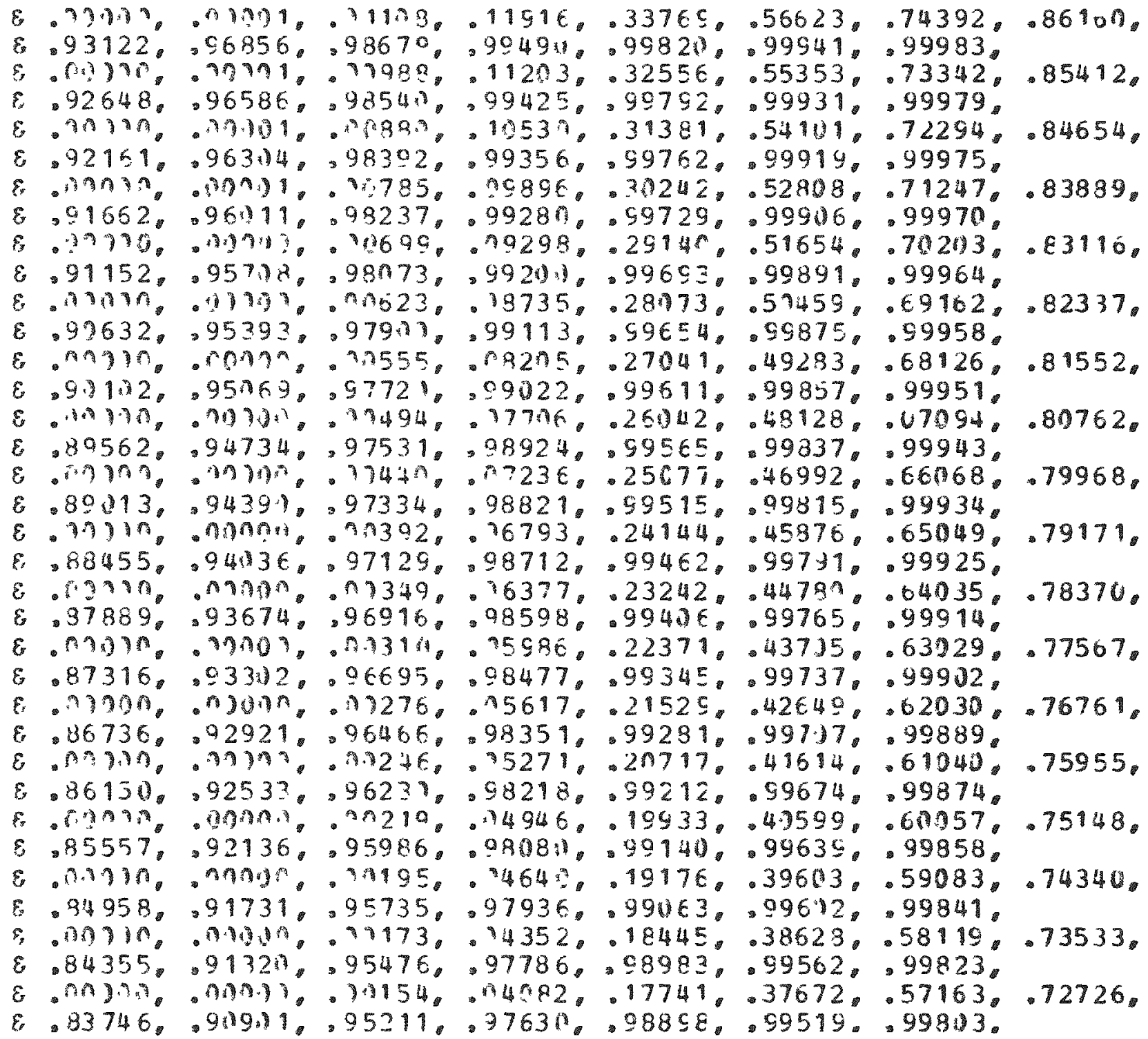




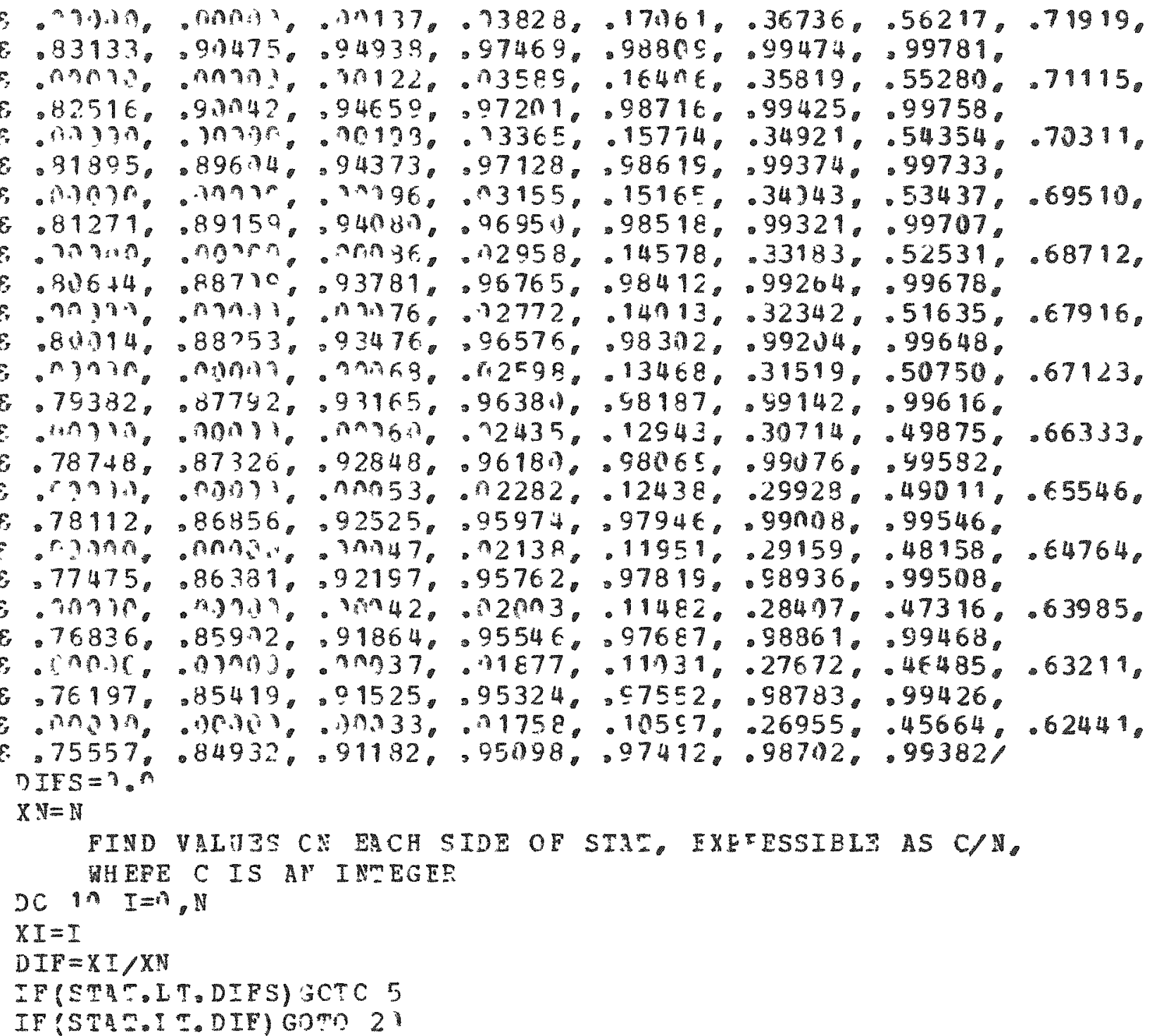




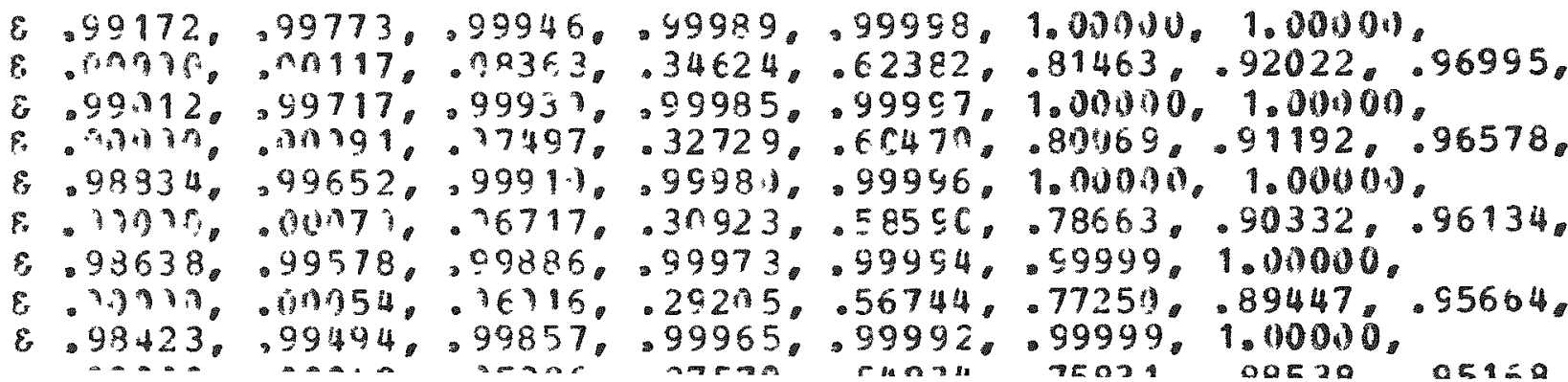

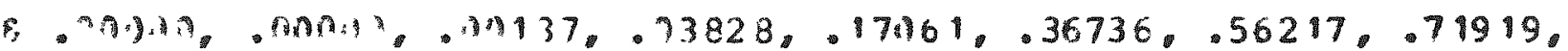
$\varepsilon .83133 . .91475 .04938 .097469 . .98809 .99474 . .99781$.

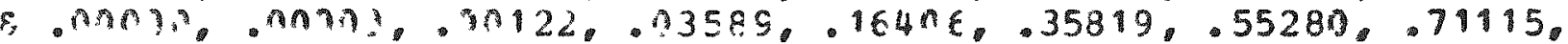
$.82516,901442,9465 \%, 97201.98716 .99425 . .99758$.

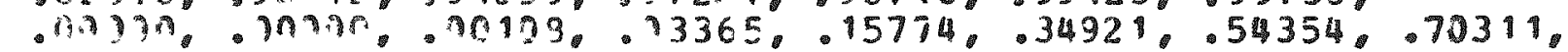
$.91805, .89614,94373.997128,98619,99374 . .99733$.

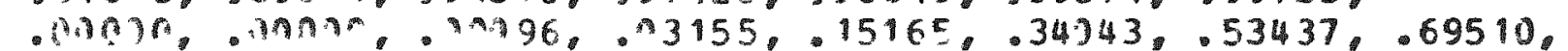
$.81271 . .89159, .9408 \%, .9695 \%, .98518, .99321 . .99707$.

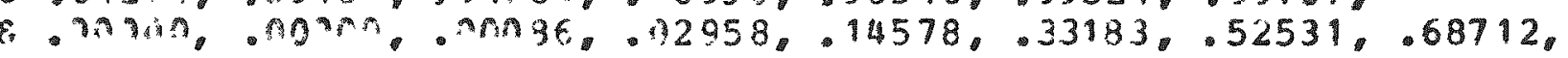
$.91644, .88770,93781, .96765, .98412, .99264 . .99678$.

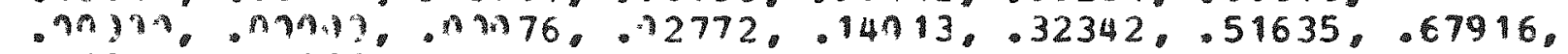
$.80114, .88753, .93476 .96576, .98302, .99204 . .99648$.

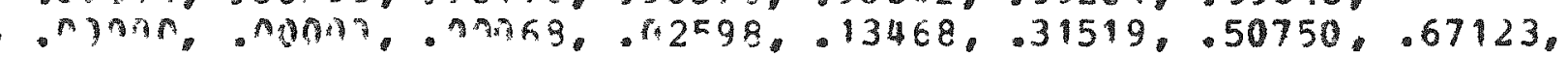
$.79382, .87792, .93165 . .96381, .98187, .99142, .99616$.

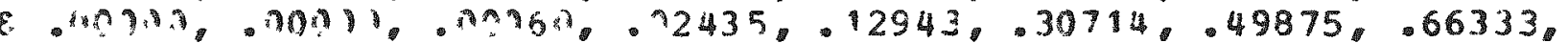
$\varepsilon .78748, .87326, .92848, .9618 \% .98065 .99476 .99592$.

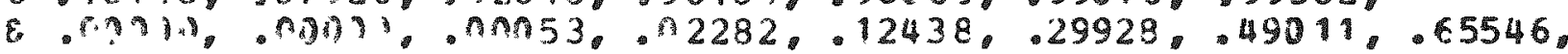
$.78112, .86856, .92525, .95974 .97946, .99008 . .99546$.

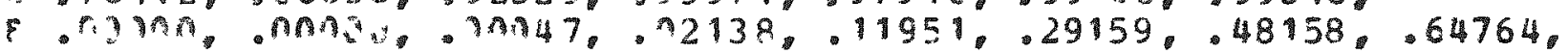
$\varepsilon .77475, .86381, .92197 .995762 .97819 . .98936 .99508$.

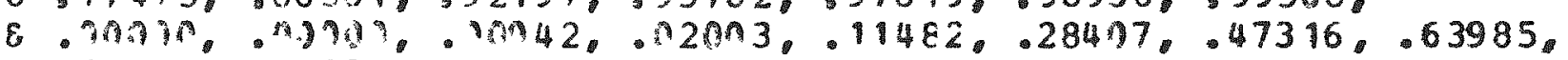
\&.76836. .85972..91864..95546. .976E7..98361..99468.

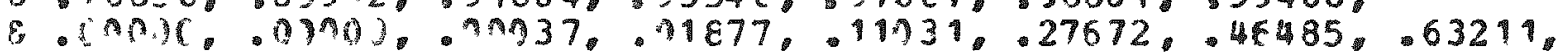
$\varepsilon .76197, .85419, .01525, .95324, .57552 . .98783 . .99426$.

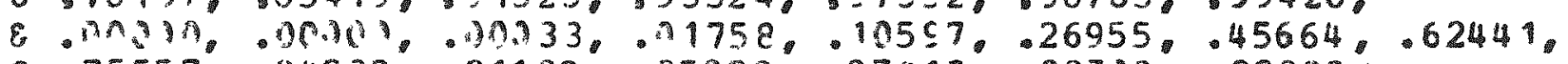
t. $75557, .84932, .91182, .95098 . .97412, .98712 . .99382 /$ DIES = .9 $X V=N$ WHERE C IS AN INEGER

SC in $I=n, N$

$X I=I$

$D I F=X I / X N$

IF (STHTIT,DIES) SCTC 5

IF $\{$ TI I.IT.DIF) GOMn 2 I 


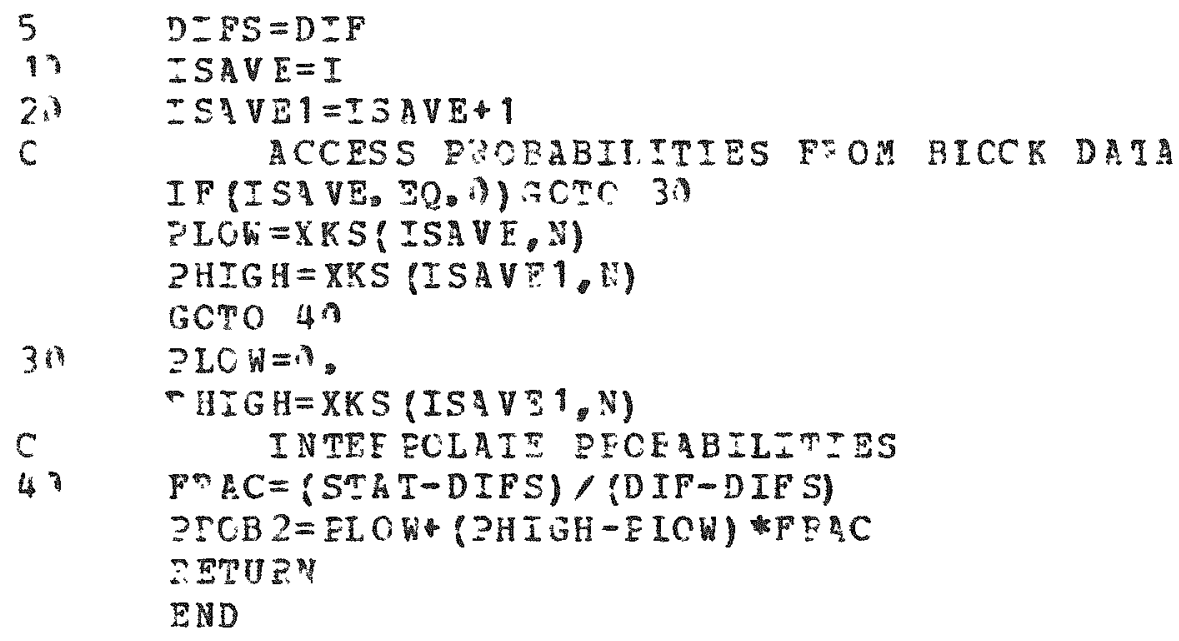


$33 / 54$

APPENDIX B. INPUT DATA USED IN SAMPLE RUN OF APPENDIX C

The data set provided here is that used in the sample run of Appendix C.

$$
\begin{aligned}
& .000270 \\
& .000460 \\
& .000410 \\
& .000092 \\
& .002100 \\
& .003900 \\
& .003000 \\
& .000770 \\
& .000024 \\
& .000480 \\
& .000180 \\
& .000970 \\
& .000074 \\
& .000430 \\
& .000130 \\
& .001100 \\
& .000780 \\
& .000210 \\
& .000290 \\
& .000990 \\
& .000078
\end{aligned}
$$



APPENDIX C. SAMPLE RUN OF KSTEST CODE

The sample run of the KSTEST code which is produced here uses file input of the data in Appendiz B. The SISORT sorting routine is selected and printing of the data file is suppressed.

This run is made in interactive mode on aEC PDP-10 computer syster.

EX KSTEST

LINK: Loading

[LNKXCT KSTEST execution]

CONE KSTEST

ENTER FORM OF IATA INFUT:HANI INFUT OR FILE? (A CHAF')

FILE

ENTER INFUT FILE NUMHER 43

ENTER NUMEEF OF IATA FOINTS TO BE USED

IIF YOU SFECIFIED FILE INFUT, O WILL CAUSE ALL FOINTS TO HE USEI:

0

AFE IATA ORIEFEI? (YESYNO)

NO

MATA INFUT COMFLETED ANALYSIS STARTEI

ANALYSIS COMFLETEI

THERE ARE 21 DATA FOINTS

WOULI YOU LIKE THEM FRINTED? (YES,NO)

YES

FANK OFIERED MATA ARE:

$\begin{array}{lr}I & \text { UALUE } \\ 1 & .2400 E-04 \\ 2 & .7900 E-04 \\ 3 & .9200 E-04 \\ 4 & .9400 E-04 \\ 5 & .1300 E-03 \\ 6 & .1800 E-03 \\ 7 & .2100 E-03 \\ 8 & .2700 E-03 \\ 9 & .2900 E-03 \\ 0 & .4100 E-03 \\ 1 & .4300 E-03 \\ 3 & .4600 E-03 \\ 3 & .4800 E-03 \\ 4 & .7700 E-03\end{array}$




$\begin{array}{ll}15 & .7800 E-03 \\ 16 & .9700 E-03 \\ 17 & .9900 E-03 \\ 18 & .1100 E-02 \\ 19 & .2100 E-02 \\ 20 & .3000 E-02 \\ 21 & .3900 E-02\end{array}$

SAMFLE SIZE

MEAN

$N=21$

STANLARD DEVIATION

$M=.7980 \mathrm{E}-03$

$K-5$ STATISTIC

SII. $1016 E-02$

LEVEL OF SIGNIFICANCE

IN - 0.2408

ALFHA $=0.1508$

ENTER R FOR RESTART, E FOF EXIT

E

ENI KSTEST

STOF

END OF EXECUTION

CFU TIME: 0.19 ELAFSEI TIME: 44.87

EXIT 
APPENDIX D. NONNORMAL THEORETICAL DISTRIBUTION FUNCTIONS

It may be desirable in some cases to have a theoretical probability distribution other than the norma1. The major modification to the code which is required for the use of other distributions is the replacement of the probability distribution function subroutine DSNORM. Several common distributions along with the corresponding DSNORM code, due to IMSL, are given below. In each case the lines of coding should be preceded by a SUBROUTINE DSNORM $(X, F)$ statement and followed by RETURN and END statements. Note that distributions 2 and 3 include these final RETURN's as numbered statements. Additional information can be found in IMSL documentation for the MDSMR subroutine.

1. Cauchy with median $\mathbf{H}$ first quartile $\mathbb{H}-\mathrm{Q}, \quad F=\operatorname{ATAN}((X-\mathbb{H}) / Q) * 0.3183099+0.5$ $Q \neq 0$

2. Uniform in $[A, B]$

If (X.GT.A) GOTO 5 where $\mathbb{B}>\mathbb{A}$

$F=0.0$

GOTO 15

5 If (X.LT.B)GOTO 10

$F=1.0$

GOTO 15

$10 \mathrm{~F}=(\mathrm{X}-\mathrm{A}) /(\mathrm{B}-\mathrm{A})$

15 RETURN

3. Exponential with mean A If $(\mathrm{X}, \mathrm{GT} .0)$ GOTO 5 $F=0.0$ GOTO 10

$5 F=1.0-\operatorname{EXP}(-X / A)$

10 RETURN

In addition to these changes which must be made to DSNORM to allow for nonnormal distributions, three lines of code must be changed in subroutine NKS as well. 
These changes are:

delete $\quad \mathbb{N}=\mathrm{XN}+0.25$

EDFI $=(\mathrm{XT}-1.375) / \mathrm{XN}$
and

$\mathrm{EDF} 2=(\mathrm{XI}-0.375) / \mathrm{XN}$
$\mathrm{EDF} 1=(\mathrm{XJ}-1.00) / \mathrm{XN}$ and

$\mathrm{EDF} 2=\mathrm{XI} / \mathrm{XN}$ 
INTERNAL DISTRIBUTION
1. C. F. Baes III
2. L. W. Barnthouse
3. J. J. Beauchamp
4. M. A. Be11
5. R. 0. Chester
6. W. D. Cottre11
7. K. E. Cowser
8. W. G. Craddick
9. W. Davis, Jx.
10. R. F. Eckerman
11-20. D. E. Fields
21. G. Ho1ton
22. S. V. Raye
23. G. D. Rex

\author{
24. C. W. Mi11er \\ 25. B. D. Murphy \\ 26. T. W. Oakes \\ 27. S. Y. Ohr \\ 28. M. R, Patterson \\ 29. D. C. Parzyck \\ 30. P. S. Rohwer \\ 31. G. Suter \\ 32. M. Yildiran \\ 33. Centra1 Research Library \\ 34. ORNL I-12 Technica1 Library \\ 35. Laboratory Records \\ 36. Laboratory Records - RC \\ 37. ORNL Patent Office
}

\section{EXTERNAL DISTRIBUTION}

38. Larry D. Carpenter, Route 2, Box 45-A, Watertown, IN 37184

39. P. R. Jaffe, Department of Civil Engineering, Princeton University, Princeton, NJ 08544

40-44. S. E. Kurtz, $2821 \mathrm{McCa}$ in Rd., Jackson, MI 49203

45. Mei-Tro Liu, Systems App1ications, Inc., 950 Northgate Drive, San Rafae1, CA 94903

46. D. Lynn Shaeffer, The BDM Corporation, 1801 Randolph Road, SE, Albuquerque, NM 87106

47. Office of Assistant Manager for Energy Research and Development, Department of Energy, Oak Ridge Operations Office, Oak Ridge. TN 37830

48-357. Given distribution as shown in TID-4500 under UC-11 and UC-41 